\title{
In-line filter included into the syringe infusion pump assembly reduces flow irregularities
}

\author{
Brotschi, B ; Grass, B ; Weiss, M ; Doell, C ; Bernet, V
}

\begin{abstract}
PURPOSE: To evaluate whether an in-line filter inserted in the syringe pump infusion line assembly influences start-up times and flow irregularities during vertical pump displacement at low infusion rates. METHODS: Fluid delivery after syringe pump start-up and after vertical displacement of the syringe pump by $-50 \mathrm{~cm}$ was determined gravimetrically at flow rates of $0.5,1.0$ and $2.0 \mathrm{ml} \mathrm{h}(-1)$. Measurements were repeated for each flow rate four times with two different syringe pumps with and without an in-line filter incorporated. Data are shown as median and range. RESULTS: Start-up times were reduced by an in-line filter at $0.5 \mathrm{ml} \mathrm{h}(-1)$ flow rate from $355.5 \mathrm{~s}(0-660)$ to $115 \mathrm{~s}(0-320)$, whereas the effect was attenuated at higher flow rates. Pooling of fluid into the infusion system after lowering the infusion syringe pump was halved in all flow rates tested. Amount of infusion bolus after elevating the syringe pump by $50 \mathrm{~cm}$ was not affected by an in-line filter. CONCLUSION: In the evaluated model in-line filters help to reduce flow irregularities and delay in drug delivery of syringe pumps at low flow rates and represent an option to optimize continuous administration of highly concentrated short-acting drugs at very small infusion rates.
\end{abstract}

DOI: https://doi.org/10.1007/s00134-011-2452-5

Posted at the Zurich Open Repository and Archive, University of Zurich ZORA URL: https://doi.org/10.5167/uzh-67337

Journal Article

Published Version

Originally published at:

Brotschi, B; Grass, B; Weiss, M; Doell, C; Bernet, V (2012). In-line filter included into the syringe infusion pump assembly reduces flow irregularities. Intensive care medicine, 38(3):518-522.

DOI: https://doi.org/10.1007/s00134-011-2452-5 


\section{B. Brotschi \\ B. Grass \\ M. Weiss \\ C. Doell \\ V. Bernet}

\section{In-line filter included into the syringe infusion pump assembly reduces flow irregularities}

Received: 6 August 2011

Accepted: 9 December 2011

Published online: 12 January 2012

(C) Copyright jointly held by Springer and ESICM 2012

B. Brotschi and B. Grass contributed equally to the study.

\section{B. Brotschi $(\bowtie) \cdot$ C. Doell}

Department of Neonatology and Intensive Care, University Children's Hospital Zurich, Steinwiesstr. 75, 8032 Zurich, Switzerland

e-mail: barbara.brotschi@kispi.uzh.ch

Tel.: +41-44-2667111

Fax: +41-44-2667168

B. Grass

Department of Neonatology, University Hospital Zurich, Frauenklinikstr. 10, 8091

Zurich, Switzerland

M. Weiss

Department of Anaesthesia, University Children's Hospital Zurich, Steinwiesstr. 75, 8032 Zurich, Switzerland

\section{Bernet}

Department of Neonatology and Intensive Care, University Children's Hospital Zurich, Steinwiesstr. 75, 8032 Zurich, Switzerland
Abstract Purpose: To evaluate whether an in-line filter inserted in the syringe pump infusion line assembly influences start-up times and flow irregularities during vertical pump displacement at low infusion rates. Methods: Fluid delivery after syringe pump start-up and after ver- tical displacement of the syringe pump by $-50 \mathrm{~cm}$ was determined gravimetrically at flow rates of 0.5 , 1.0 and $2.0 \mathrm{ml} \mathrm{h}^{-1}$. Measurements were repeated for each flow rate four times with two different syringe pumps with and without an in-line filter incorporated. Data are shown as median and range. Results: Start-up times were reduced by an in-line filter at $0.5 \mathrm{ml} \mathrm{h}^{-1}$ flow rate from $355.5 \mathrm{~s}$

(0-660) to $115 \mathrm{~s}(0-320)$, whereas the effect was attenuated at higher flow rates. Pooling of fluid into the infusion system after lowering the infusion syringe pump was halved in all flow rates tested. Amount of infusion bolus after elevating the syringe pump by $50 \mathrm{~cm}$ was not affected by an in-line filter.

Conclusion: In the evaluated model in-line filters help to reduce flow irregularities and delay in drug delivery of syringe pumps at low flow rates and represent an option to optimize continuous administration of highly concentrated short-acting drugs at very small infusion rates.

Keywords Infusion pump - Syringe · In-line filter - Compliance . Complications $\cdot$ Equipment

\section{Introduction}

Prompt infusion start-up and continuous delivery of highly concentrated short-acting drugs at low infusion rates from pressure-controlled infusion pumps are hampered by intrinsic compliance. Syringe pump gaps and syringe and infusion line compliance facilitate fluid pooling into or fluid emptying from the system during vertical pump displacement and result in start-up delays [1-11].
In-line filters in an infusion line assembly represent a resistance element necessitating a higher driving pressure. We hypothesize that insertion of an in-line filter between infusion syringe and infusion line increases intra-syringe pressure shifting the volume pressure curve to a less compliant range. A reduced compliance helps to improve start-up times as well as stabilise steady state flow characteristics during vertical pump displacement. Thus, the aim of this study was to evaluate whether an in-line filter inserted in the syringe pump infusion line assembly 
influences start-up times and flow irregularities during vertical pump displacement at low infusion rates.

\section{Methods}

Experimental set-up

In an in vitro set-up, start-up times and steady state performance during hydrostatic pressure changes were evaluated using a standard syringe infusion pump with and without an in-line filter.

An Alaris Asena ${ }^{\circledR}$ GH syringe pump (IVAC Medical Systems, Hampshire, UK) was used with 50-ml Fresenius infusion syringes (Fresenius AG, Bad Homburg, Germany). A neonatal Pall in-line filter device (Pall Posidyne Neo Filter $0.2 \mu \mathrm{m}$, Pall AG Switzerland, Basel, Switzerland) coupled with a stopcock was included between one $200-\mathrm{cm}$ and one $10-\mathrm{cm}$ non-compliant infusion line (PE-Infusion Line, Acromed AG, Regensdorf, Switzerland) which was connected to a 22-Gauge 10-cm central venous line (Teleflex Medical $\mathrm{GmbH}$, Belp, Switzerland) (Fig. 1).

For each experiment, the syringe was filled with $0.9 \%$ normal saline and inserted into the syringe pump. An automated priming procedure (extrusion of a $0.5-\mathrm{ml}$ fluid bolus) was performed prior to start in order to overcome any mechanical gaps within the system.

For all experiments with and without an in-line filter, the tip of distal end of the central venous line was immersed by $7 \mathrm{~cm}$ in a sampling glass filled with distilled water. In order to simulate a central venous pressure of $7 \mathrm{mmHg}$, the pump outlet was positioned at the level of the immersed central venous line tip. A thin layer of oil covered the water surface to avoid any fluid evaporation. Assuming a specific weight of $0.9 \%$ normal saline of $1 \mathrm{~g} \mathrm{ml}^{-1}$ at room temperature, fluid delivery $\left(\mathrm{ml} \mathrm{h}^{-1}\right)$ into the sampling beaker was gravimetrically determined using an electronic balance (AG 204-Delta-Range ${ }^{\circledR}$, Mettler Toledo, Schwerzenbach, Switzerland; sensitivity
$0.0001 \mathrm{~g}$ ). The balance data output was recorded in 10-s intervals by an IBM-compatible personal computer employing software specifically written for this purpose (MCPS V2.6-CAD, Software GmbH, Mönchengladbach, Germany).

Experiments performed

\section{Start-up and steady state performance}

The pumps were started at an infusion rate of $0.5 \mathrm{ml} \mathrm{h}^{-1}$. Elapsed time from depressing the start button to first fluid delivery as indicated by the electronic balance (TTFFD $=$ time to first fluid delivery) and time until achieving $95 \%$ of steady state flow (TTSSF95 = time to $95 \%$ steady state flow) were recorded.

\section{Vertical pump displacements}

At steady state flow conditions, the pumps were lowered by $50 \mathrm{~cm}$ and the resulting retrograde aspiration volume (RAV, amount of fluid backflow into the syringe infusion line assembly), zero drug delivery time (ZDDT) and no flow time (NFT, backflow time and steady state until forward flow appears) were assessed. Since the pumplowering manoeuvre is followed by an immediate weight drop on the balance due to fluid backflow from the beaker towards the tubing, ZDDT was defined as the time interval between pump lowering and re-attainment of the beaker weight that was measured immediately before vertical pump displacement. After steady state flow delivery was re-established, the pump was elevated to its original vertical position.

At steady state flow conditions, the pumps were elevated by $50 \mathrm{~cm}$, resulting in the release of an infusion bolus (IB) and an overshooting flow rate as a result from the immediate hydrostatic pressure relief.

Each experiment was performed four times using two syringe pumps with and without an in-line filter at flow
Fig. 1 Study design for in vitro measurements

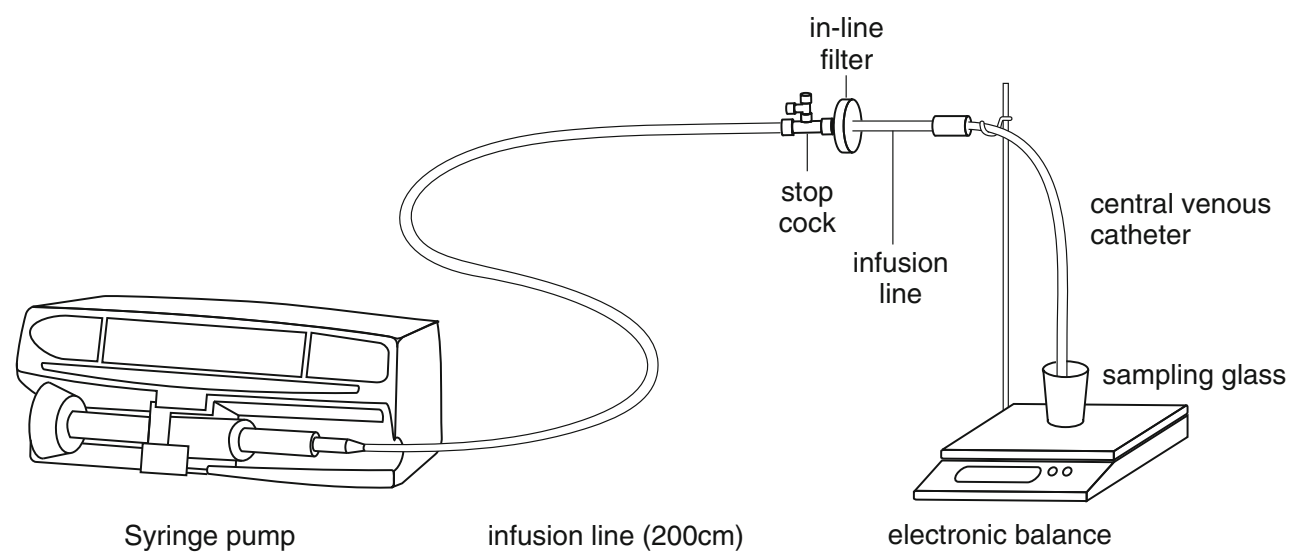


rates of $0.5,1.0,2.0 \mathrm{ml} \mathrm{h}^{-1}$ (total $=4 \times 2 \times 2 \times$ $3=48$ measurements). All experiments were done in a randomized order at $22-24^{\circ} \mathrm{C}$ ambient temperature.

Data were compared using Mann-Whitney $U$ test. Data are presented as median and range because of abnormal distribution. A $p$ value of less than 0.05 was considered statistically significant. Data analysis was performed using Microsoft Office Excel 2003, SPSS Statistics 17.0 and IDL 7.1 (ITT Visual Information Solutions).

\section{Results}

Measured or calculated parameters are summarized in Table 1. Comparing all three different flow rates the highest TTFFD is measured at $0.5 \mathrm{ml} \mathrm{h}^{-1}$ with and without an in-line filter. TTFFD was not significantly influenced by an in-line filter at all flow rates, although it is more than halved by an in-line filter at $0.5 \mathrm{ml} \mathrm{h}^{-1}$. However, TTSSF95 was reduced significantly by an inline filter at 0.5 and $2.0 \mathrm{ml} \mathrm{h}^{-1}$, whereas the effect was not shown at $1.0 \mathrm{ml} \mathrm{h}^{-1}$ flow rate. In summary, start-up delay is not augmented by an in-line filter.

Fluid pooling into the infusion system, as indicated by NFT, ZDDT and RAB, was reduced by half with an in-line filter during lowering the syringe pump by $50 \mathrm{~cm}$ at all flow rates. Amount of infusion bolus after elevating the syringe pump by $50 \mathrm{~cm}$ was not affected by the inclusion of an in-line filter. Figure 2 shows the results obtained at 0.5 and $2.0 \mathrm{ml} \mathrm{h}^{-1}$ flow rates.

\section{Discussion}

The aim of this pilot study was to evaluate whether an in-line filter inserted in the syringe pump infusion line assembly influences start-up times and flow irregularities during vertical pump displacement at low infusion rates in the evaluated model.

The main findings of the study were that TTFFD was halved by the in-line filter at an infusion rate of $0.5 \mathrm{ml} \mathrm{h}^{-1}$ and TTSSF95 was significantly shorter with an in-line filter at an infusion rate of 0.5 and $2.0 \mathrm{ml} \mathrm{h}^{-1}$, whereas this effect could not be shown at $1.0 \mathrm{ml} \mathrm{h}^{-1}$ flow rate. Similarly, fluid pooling into the infusion system was reduced by half with an in-line filter included in the infusion line assembly during lowering the syringe pump by $50 \mathrm{~cm}$. Although some data are not statistically significant, all data show a tendency to reduced flow irregularities. In neonatal and paediatric intensive care highly concentrated short-acting drugs like catecholamines often run on low infusion rates. According to the data obtained in this study, the

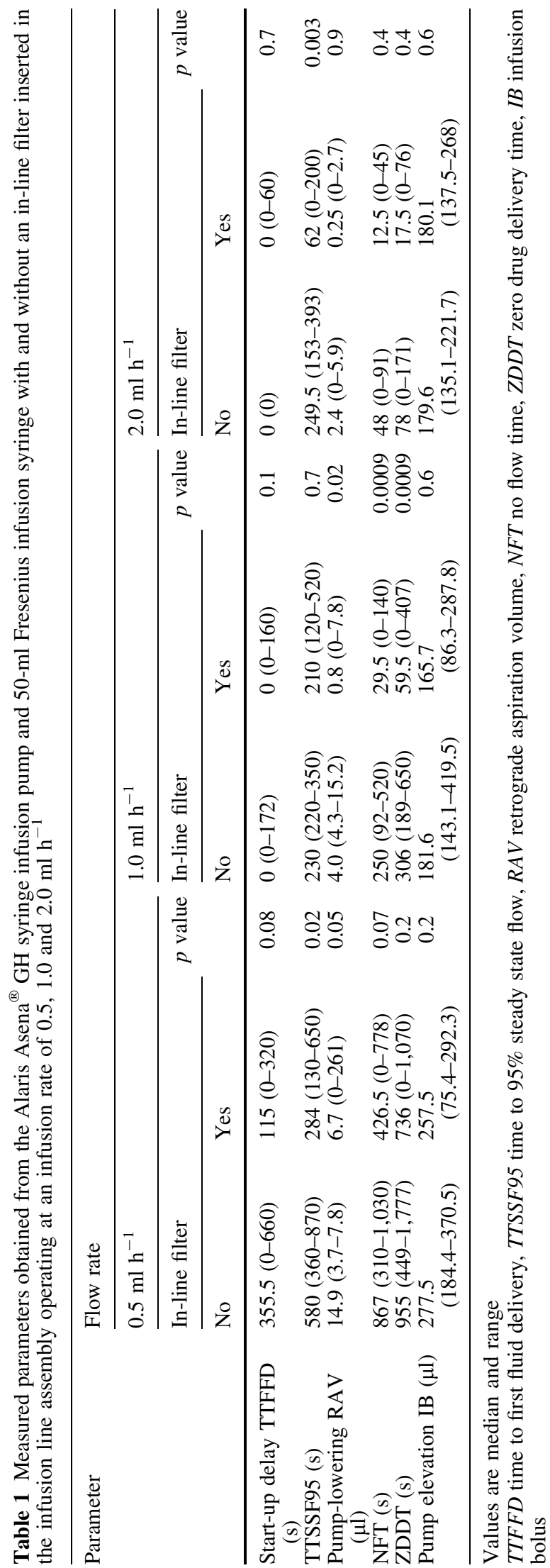




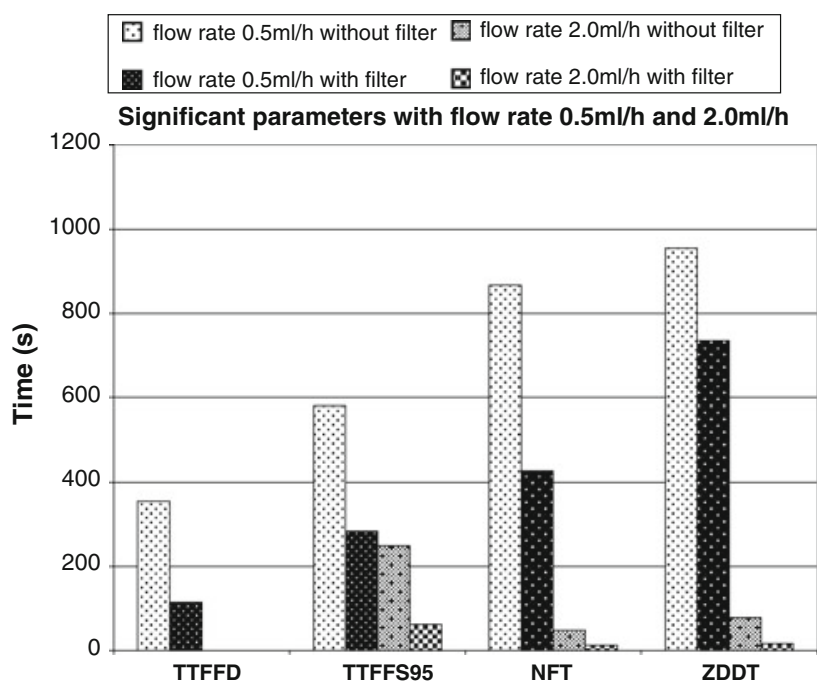

Fig. 2 Measured parameters obtained from the Alaris Asena ${ }^{\circledR} \mathrm{GH}$ syringe infusion pump and 50-ml Fresenius infusion syringe with and without an in-line filter inserted in the infusion line assembly operating at an infusion rate of 0.5 and $2.0 \mathrm{ml} \mathrm{h}^{-1}$. Values are median. TTFFD time to first fluid delivery, TTSSF95 time to $95 \%$ steady state flow, NFT no flow time, ZDDT zero drug delivery time

reduction of flow irregularities by in-line filters may lead to a stabilization of circulation and blood pressure during syringe/line change and on transport. Further investigations are necessary to prove these potential benefits.

Flow irregularities are mainly caused by compliance of the infusion line, the syringe and the pump. In the past several attempts to reduce compliance and to overcome these shortcomings of infusion syringe pumps were performed. The FASTSTART procedure seems to be effective and substantial improvements can be obtained by priming the system prior to starting [4]. Syringe design, syringe pump design and different tested pumps led to clinically relevant flow irregularities during vertical displacement [5-7]. Smaller syringes, two-piece syringes and infusion rates greater than $1 \mathrm{ml} \mathrm{h}^{-1}$ are recommended when highly concentrated drugs are administered $[6,9,10]$, but often flow rates less than $1 \mathrm{ml} \mathrm{h}^{-1}$ are necessary in neonatal and paediatric patients.
The costs of these in-line filters must be calculated as most of the children need several drug infusions with integrated in-line filters and these in-line filters have to be replaced every 72-96 h. But this low-cost device seems to have other positive effects in addition to those mentioned above. In-line filters interposed in intravenous infusion systems may prevent the accidental administration of particles, precipitated drugs, microorganisms, endotoxins and air $[12,13]$. A number of studies have demonstrated that if integrated into a package of measures, the costs of in-line filters can be offset against other savings [14, 15].

A few limitations of this study must be acknowledged. Real patient features (e.g. undulating venous pressure, presence of other infusion pumps delivering through the same catheter lumen) may introduce additional factors that alter the observed effects. Not all of our results are statistically significant most likely because of the small number of experiments. In our study we did not analyse the influence of material, length, diameter of the lines and resistance of the in-line filters. Some of these aspects were investigated in previous studies $[6,8,9]$. Our findings have to be confirmed by other studies including different set-up, materials and higher flow rates.

On the basis of our study findings in-line filters help to reduce flow irregularities and delay in drug delivery and may represent a further step in reducing complianceinduced flow irregularities in syringe pump infusion systems, particularly at lower flow rates. We could show in the evaluated model using this syringe pump and in-line filter combination that in-line filters represent an option to optimize continuous administration of highly concentrated short-acting drugs at very small infusion rates. In-line filters can be easily inserted and used with all fluids except blood products and lipids. This study could be the first step to evaluate a new measure to reduce flow irregularities, but further work is required to validate this approach for all different pump/syringe/filter combinations.

Acknowledgments We thank René Bolz (hospital medical technician) for his technical support and Susanne Staubli (graphic artist) for her support.

\section{References}

1. Rooke GA, Bowdle TA (1994) Syringe pumps for infusion of vasoactive drugs: mechanical idiosyncrasies and recommended operating procedures. Anesth Analg 78:150-156

2. Lonnqvist PA, Lofqvist B (1997) Design flaw can convert commercially available continuous syringe pumps to intermittent bolus injectors. Intensive Care Med 23:998-1001
3. Kern H, Kuring A, Redlich U, Dopfmer UR, Sims NM, Spies CD, Kox WJ (2001) Downward movement of syringe pumps reduces syringe output. $\mathrm{Br} \mathbf{J}$ Anaesth 86:828-831

4. Neff T, Fischer J, Fehr S, Baenziger O, Weiss M (2001) Evaluation of the FASTSTART mode for reducing startup delay in syringe pump infusion systems. Swiss Med Wkly 131:219-222
5. Neff T, Fischer J, Fehr S, Baenziger O, Weiss M (2001) Start-up delays of infusion syringe pumps. Paediatr Anaesth 11:561-565

6. Weiss M, Fischer J, Neff T, Baenziger $\mathrm{O}$ (2000) The effects of syringe plunger design on drug delivery during vertical displacement of syringe pumps. Anaesthesia 55:1094-1098 
7. Neff TA, Fischer JE, Schulz G, Baenziger O, Weiss M (2001) Infusion pump performance with vertical displacement: effect of syringe pump and assembly type. Intensive Care Med 27:287-291

8. Weiss M, Baenziger O, Neff T, Fanconi S (2000) Influence of infusion line compliance on drug delivery rate during acute line loop formation. Intensive Care Med 26:776-779

9. Weiss M, Hug MI, Neff T, Fischer J (2000) Syringe size and flow rate affect drug delivery from syringe pumps. Can J Anesth 47:1031-1035
10. Cook RI (2000) Syringe pump assemblies and the natural history of clinical technology. Can J Anesth 47:929-935

11. Leff RD, True WR, Roberts RJ (1987) A gravimetric technique for evaluating flow continuity from two infusion devices. Am J Hosp Pharm 44:1388-1391

12. Trautmann M, Zauser B, Wiedeck H, Buutenschön K, Marre R (2001) Bacterial colonization and endotoxin contamination of intravenous fluids. J Hosp Infect 37:225-236
13. Jack T, Brent BE, Boehne M, Müller M, Sewald K, Braun A, Wessel A, Sasse M (2010) Analysis of particulate contaminations of infusion solutions in a pediatric intensive care unit. Intensive Care Med 36:707-711

14. Kunac DL, Ball PA, Broadbet RS (1999) In-line intravenous filtration in neonates: help not hindrance. Aust J Hosp Pharm 29:321-327

15. Ball PA (2003) Intravenous in-line filters: filtering the evidence. Curr Opin Clin Nutr Metab Care 6:319-325 